\title{
Global Progress Towards Sustainable Forest Management - Bright Spots and Challenges
}

Kenichi Shono ( $\nabla$ kenichi.shono@fao.org)

Food and Agriculture Organization of the United Nations

\section{Research Article}

Keywords: sustainable forest management, forest degradation, forest productivity, ecosystem services

Posted Date: August 20th, 2021

DOl: https://doi.org/10.21203/rs.3.rs-744670/v1

License: (c) This work is licensed under a Creative Commons Attribution 4.0 International License. Read Full License

Version of Record: A version of this preprint was published at International Forestry Review on March 1st, 2022. See the published version at https://doi.org/10.1505/146554822835224856. 


\section{Abstract}

Sustainable forest management is an imperative response to continuing deforestation and forest degradation, and the associated decline in forest productivity and supply of ecosystem services. This paper analyses progress towards sustainable forest management globally as well as by climatic domains and national income levels using data from the Global Forest Resources Assessment 2020. It also examines progress towards sustainable forest management relate to the presence of enabling factors. The findings reveal global expansion of sustainable forest management supported by the widespread presence of enabling framework as manifested in the slowing rate of forest loss in large deforesting countries, increase in forest area designated for conservation, and the rapid expansion of certified forest area. However, such progress has been uneven, and the rate of forest loss is accelerating in tropical low-income countries. In addition to inadequate forest governance in general, factors contributing to this deterioration include: low coverage of long-term forest management plans; high proportion of forests without designated management objectives; and unclear ownership of forests. To enhance the implementation of sustainable forest management in these priority geographies, this paper proposes conservation through sustainable use, including strengthening the role of well-managed production forests in maintaining forest cover and ecosystem services at the landscape level.

\section{Introduction}

Forest and trees make essential contributions to life on earth, providing clean air, regulating water cycle, supporting the majority of world's terrestrial biodiversity, responding to climate change and bolstering livelihoods ${ }^{1}$. Sustainable forest management seeks to balance the provision of various forest products and services and to maintain them for the long-term. The global definition adopted by the United Nations captures the common understanding of sustainable forest management as a "dynamic and evolving concept, which aims to maintain and enhance the economic, social and environmental values of all types of forests, for the benefit of present and future generations" ${ }^{2}$. This definition considers the following seven thematic elements as a reference framework: 1) extent of forest resources; 2) forest biodiversity; 3 ) forest health and vitality; 4) productive functions of forest resources; 5 ) protective functions of forest resources; 6) socio-economic functions of forests; and 7) legal, policy and institutional framework.

The critical importance of sustainable forest management as a response to continuing deforestation and forest degradation, and the associated decline in productivity and supply of ecosystem services, is widely recognized. Sustainable forest management contributes significantly to the achievement of 2030 Agenda for Sustainable Development on multiple fronts, with the most direct impact on Sustainable Development Goal (SDG) 15 "Life on land". It is also an integral part of global efforts to promote forest and landscape restoration. As well, sustainable forest management is a key element of the United Nations Strategic Plan for Forests 2017-2030 (UNSPF), which provides a global framework for action at all levels to sustainably manage all types of forests and trees outside forests, and to halt deforestation and forest degradation ${ }^{3}$. Moreover, with the ongoing COVID-19 pandemic, the role of sustainably managed forests and trees in contributing to the social and economic recovery in the aftermath of the crisis is considered crucial. 
Progress towards sustainable forest management is inherently difficult to measure as managing forests sustainably requires a balanced approach encompassing the three pillars of sustainability - economic, social and environmental. Measuring progress in each of these broad areas in a meaningful way is complex and often not fully achievable ${ }^{4}$. As such, progress in sustainable forest management is measured through proxy indicators including changes in forest cover and condition, presence of enabling conditions, expression of intent to manage forests sustainably, and the application of instruments that mandate sustainable management of forests.

Substantial progress has been made towards sustainable forest management in recent decades, as revealed by FAO's Global Forest Resources Assessment (FRA) 2015 and 20204,5,6. The latest SDG progress monitoring result also confirms the global expansion of sustainable forest management ${ }^{7}$. Based on the monitoring of SDG indicator 15.2.1 "progress towards sustainable forest management", the only areas showing negative changes are: 1) annual rate of net forest area change in Southeast Asia, Northern Africa and Sub-Saharan Africa; 2) above-ground forest biomass in Australia and New Zealand; and 3) certified forest area in Northern Africa and Sub-Saharan Africa. Furthermore, reporting of progress on UNSPF highlights a number of successes and positive trends towards achieving the six UNSPF Global Forest Goals ${ }^{3}$.

These high-level global and regional analyses of indicators for sustainable forest management are useful in understanding the general trends, which has been positive overall. However, global and regional averages can be heavily influenced by trends in large forested countries, masking worrying situations in smaller forested countries that may require attention. As well, some regions are notably diverse and include countries along a wide spectrum of socio-economic contexts, ecosystem types and governance regimes. In such cases, regional groupings are less compelling as a unit sharing some common characteristics relevant to forest management. Furthermore, these existing analyses do not explicitly examine the link between the presence of enabling conditions for sustainable forest management and the changes in the extent and condition of forests on the ground. In principle, the presence of enabling framework and intent for sustainable forest management should be correlated with stable or increasing forest cover. However, the actual situation in practice is much more complex as the quality and implementation of forest policies and measures are variable, and these aspects are not easily quantifiable.

This paper provides analyses of key indicators of sustainable forest management to understand progress in enabling and implementing sustainable forest management at the global, national and operational levels. Analyses of FRA data by climatic domains and national income categories provide insights into how forests and forest management are changing, and where the challenges and opportunities for sustainable forest management are the greatest. The paper also examines how forest management objectives relate to the pattern of changes in forest area, and assesses the impact of enabling conditions and tools for sustainable forest management in stabilizing forest cover. The findings will inform approach and design of future support to expand sustainable forest management where most needed to bring a about actual improvements in the way forests are managed. 


\section{Results}

\section{Distribution of forests by climatic domain and income}

In 2020 , the world had 4.06 billion hectares of forest, $45 \%$ of which are found in the tropics, $27 \%$ in the boreal domain, $16 \%$ in the temperate zone, and $11 \%$ in the subtropics ${ }^{5}$. There is unevenness in the income of countries that make up forests in different climatic domains. High-income countries account for $67 \%$ of temperate forests, $42 \%$ of subtropical forests, $33 \%$ of boreal forests, and almost none of the tropical forests. On the other hand, tropical forests comprise $97 \%$ of the forest area of low-income countries and $90 \%$ of forests in lower middle-income countries. The majority (53\%) of the world's forest area are found in the upper middle-income countries while $25 \%, 14 \%$ and $8 \%$ are found in high-income, lower middleincome and low-income countries, respectively (Fig. 1).

\section{Changes in forest area}

The extent of boreal, temperate and subtropical forests have consistently increased between 1990 and 2020 , although the rate of increase has slowed slightly in 2010-2020 compared to the two preceding decades. Net gains in forest area were the greatest in the subtropical domain. On the other hand, topical forests continue to be lost at a considerable rate, although the rate of loss has been decreasing (Fig. 2). Magnitude of net forest loss in the tropics far exceeds forest gains in the other climatic domains, with more than 90 percent of deforestation during 1990-2020 occurring in the tropical domain ${ }^{5}$.

Analyses of forest area change by national income reveals the widening gap between high and low income countries. From 1990 to 2000, there was a very high rate of forest loss among the group of countries that are presently in the upper middle-income category. However, the rate of loss has slowed substantially during the past 20 years, with the annual of loss of 5.1 million ha between 1990-2000 falling to 1.5 million ha/year between 2010 and 2020. Conversely, the rate of net forest loss is accelerating in low-income and lower middle-income countries, indicating deterioration of forest management in these countries. In the high-income countries, forest area has continued to increase and the rate of gain is increasing (Fig. 3).

Net forest loss during the previous 30 years have occurred almost entirely in the tropics, with the highest rate of loss occurring in the low-income countries (Table 1). For net gains in forest area, on the other hand, substantial increase between 1990 and 2020 was observed in the upper middle-income countries in temperate ( $10 \%$ increase) and subtropical ( $20 \%$ increase) domains. Boreal and temperate forests have remained relatively stable at the global level, while subtropical forests have expanded significantly. 
Table 1

Net changes in forest area (percentage) 1990-2020 by climatic domain and income category

\begin{tabular}{|llllll|}
\hline & Boreal & Temperate & Subtropical & Tropical & Avg. \\
\hline High-income & $0.2 \%$ & $3.6 \%$ & $4.8 \%$ & $-1.1 \%$ & $2.4 \%$ \\
\hline Upper middle-income & $1.4 \%$ & $10.4 \%$ & $19.9 \%$ & $-13.5 \%$ & $-4.0 \%$ \\
\hline Lower middle-income & $-1.2 \%$ & $9.1 \%$ & $1.1 \%$ & $-10.7 \%$ & $-9.3 \%$ \\
\hline Low-income & - & $-11.8 \% *$ & $9.7 \% * *$ & $-15.2 \%$ & $-15.1 \%$ \\
\hline Avg. & $1.0 \%$ & $5.4 \%$ & $12.2 \%$ & $-12.9 \%$ & \\
\hline * Forest loss entirely due to reduction of forest area in DPR Korea & \\
** Forest gain entirely due to increase in forest area in Syria & & \\
\hline
\end{tabular}

\section{Forest management objectives}

Forests can be managed for one or a combination of objectives. Forests provide multiple goods and services, certain combinations of which can be prioritized and optimized through management prescriptions. Often, there are trade-offs between the different ecosystem services provided by forests, and careful consideration is needed to balance these different forest benefits, for example between wood production, mitigation of soil erosion and biodiversity conservation ${ }^{8}$. As societal expectations on the roles of forests evolve, so do the objectives of forest management.

Globally, proportions of forest area designated for production, social services, and multiple use as primary management objective have been stable during the previous 30 years, while proportion allocated for protection of soil and water and biodiversity conservation have consistently increased. Forest area without a designated primary management objective have decreased steadily during this period (Fig. 4).

Although the proportion of forest area allocated for multiple use as the primary objective has not changed considerably, the number of countries that have some forest area managed either as multiple use forest or with multiple objectives (primary and secondary objectives) have increased from 98 countries/territories in 1990 to 120 in 2020.

Countries in the low-income and lower middle-income categories have lower proportions of their forest area designated for production and higher proportions designated for biodiversity conservation compared to the higher income countries. Conversely, high-income and upper middle-income countries have higher proportion designated for production and lower proportion for biodiversity conservation. High-income countries have the largest proportion, $30 \%$ of total forest area, allocated to multiple use as the primary management objective among the income categories (Fig. 5). 
Another characteristic of lower income countries is the high proportion of forests that have no designated management objectives. In fact, just over half of the total forest area of low-income countries have no management objective. Forests without any designated management objectives are likely to be subjected to unplanned and unsustainable utilization, leading to degradation and loss of economic, ecological and social values, and resulting in deforestation.

There are stark differences in the objectives of forest management among the climatic domains. Boreal forests are characterized by the high proportion, nearly $50 \%$ of total forest area, designated primarily for production. At the other end of the climatic range, tropical forests have the lowest proportion allocated for production and the highest proportion designated for biodiversity conservation, which could be a reflection of the relative conservation value of tropical forests. More than $1 / 3$ of tropical forest do not have any designated management objectives (Fig. 6).

\section{Policies and legislations supporting SFM}

The presence of supportive policy and legal framework is an important enabling condition for sustainable forest management ${ }^{9}$. Countries that have policies and legislations that explicitly encourage and support sustainable forest management cover $99 \%$ of the global forest area. Approximately half of the countries that have such policies and legislations have them at both national and sub-national levels. The presence of policies and legislations did not differ significantly across climatic domains and national income categories.

Well-formulated and effectively implemented forest polices and legislations plays a key part in advancing sustainable forest management. However, the mere presence of such framework do not necessarily translate to realization of sustainable forest management on the ground. Developing policies that work in practice is difficult ${ }^{9}$. An extensive review has found that effectiveness of policy instruments in actually improving forest management and conservation is moderate on average ${ }^{10}$. In recent years, there has been a shift in approach to forest conservation from relying solely on government policies and regulations to an increased emphasis on market-based initiatives ${ }^{11}$.

\section{Stakeholder platforms}

The participation of stakeholders in forest management decision-making can be a powerful vehicle for moving towards sustainability and improving local livelihoods. It is also critical for the legitimacy and effectiveness of national forest programmes ${ }^{12}$. Effective engagement of stakeholders can balance the different land use interests, minimize conflicts, support new partnerships among communities, government and the private sector, and contribute to sustainable use and conservation of forests ${ }^{13}$.

In FRA 2020, 143 of the 236 countries and territories reported having in place a stakeholder platform, defined as a recognized procedure that a broad range of stakeholders can use to provide inputs into the 
development of national forest policy ${ }^{14}$. These countries account for $95 \%$ of the global forest area. The widespread presence of stakeholder platforms reflects the recognition of the importance of engaging various actors across sectors and the role of indigenous peoples and local communities (IPLC) in contributing to sustainable management of forest resources ${ }^{15}$. While the prevalence of such platforms is encouraging, the actual extent to which these mechanisms are used and their effectiveness are variable.

\section{Permanent forest estate}

Permanent forest estate refer to forest area that is designated to be retained as forest and may not be converted to other land use. In principle, these represent forest areas for which a commitment has been made to sustain forest values well into the future ${ }^{6}$. In 2020, 1.97 billion ha were reported as permanent forest estate, accounting for $48 \%$ of the total global forest area. By climatic domain, boreal zone has the largest proportion of the domain forest area in permanent forest estates at $89 \%$, followed by the temperate domain at $59 \%$. On the other hand, only about a quarter of subtropical and tropical forests are designated permanent forest estate. Distribution of permanent forest estates is also highly variable by income. Vast majority, $87 \%$, of permanent forest estate areas are found in high- and upper middle-income countries, while only $2.6 \%$ are found in low income countries.

\section{Forest area with long-term forest management plan}

The presence of forest management plans indicates the intention to manage forests for long-term purposes ${ }^{4}$. In this study, forest area with long-term forest management plan refer to forest area that has a long-term (ten years or more) documented management plan, aiming at defined management goals, and which is periodically revised ${ }^{14}$.

There has been a steady increase in the total forest area covered by forest management plans globally in the past 30 years. The increase has been the most prominent in the tropics where such areas nearly doubled between 1990 and 2020. In the subtropical domain, there was also a substantial increase of $65 \%$. Increases in temperate and boreal forests have been more modest (Fig. 7).

Despite the significant increase in recent decades, the proportion of forest area covered by forest management plans remains modest in the tropics at only $21 \%$. The highest coverage is found in the boreal domain (88\%), followed by temperate (65\%) and subtropical (51\%) domains (Fig. 9).

When viewed by income, forest area covered by forest management plans is highest in high-income countries and declines as income level decreases. Particularly concerning is the very low coverage in the low-income countries where only $12 \%$ of the forest have forest management plans (Fig. 9).

Main reasons for the low coverage of forest management plans in lower income tropical countries include inadequate funding and capacity to formulate them, as well as absence of vision for the 
development and sustainable use of forest resources ${ }^{16}$. In addition to the low coverage, the quality and implementation of forest management plans were they do exist are also a concern. In many tropical countries, the responsibility of drawing up forest management plans often rest with the concessionaires or logging companies ${ }^{17,18}$. Under such arrangement, timber harvesting take precedence without adequate attention given to the full range of products and services provided by forests.

\section{Forest area within legally established protected areas}

Protected areas have been a leading strategy in biodiversity conservation $19,20,21$. Currently, $12 \%$ of the world's forests are in legally established protected areas (including IUCN Categories I - IV but excluding Categories $\mathrm{V}-\mathrm{VI}$ ). Forests inside protected areas increased substantially, by $60 \%$ globally, between 1990 and 2020. In the boreal, temperate and subtropical domains, forests in protected areas more than doubled. In the tropics, gains were more modest at 44\% increase between 1990 and 2020 (Fig. 10). Tropical forests comprise the overwhelming majority $(72 \%)$ of the global forest area within legally established protected areas.

Proportion of total forest area in the domain located in protected areas is the lowest in boreal zone (5\%), increase towards the warmer climate (13\% in temperate and subtropical domains, reaching $28 \%$ for tropical forests. Viewing the trends by wealth, high-income countries have the lowest percentage of their forest area in legally protected areas, while more than a $1 / 4$ of forests in lower middle-income countries are in protected areas (Fig. 11).

The large portion of tropical forests designated as protected areas is indicative of the their importance in protecting globally significant biodiversity as well as the perception that declaring protected status represents the best, and sometimes the only, option for conserving forests of high conservation value in developing tropical countries. Higher income countries, on the other hand, employ a diversity of strategies to maintain forests, including through multiple use, without necessarily designating them as protected areas.

\section{Forest ownership}

Forest ownership is not necessarily an indicator of sustainable forest management as different types of forest owners including governments, individuals, private sector companies and local communities could all be responsible stewards of forest resources. There is a perspective that tenure security offered by private ownership has contributed to effective self-regulation of forest management in the temperate zone ${ }^{22}$. It is further argued that tenure security would encourage investment in sustainable forest management. However, even with secure tenure, it is clear that some form of regulation would still be necessary to ensure responsible forest management as forest owners and managers seeking to maximize profits would likely prioritize short-term revenues particularly in developing countries where political uncertainties add to the inherent risks of biological production. 
Globally, 75\% of the total forest area was under public ownership in 2015 (the latest year for which data is available), while $22 \%$ was privately owned. High-income countries have the highest percentage of forest area under private ownership at $37 \%$, which declines with national income levels to less than $4 \%$ in low-income countries. By climatic domain, boreal forest is characterized by its largely public ownership at $91 \%$. Private ownership is more common in subtropical and temperate forests, where $41 \%$ and $34 \%$ of the domain forest area are privately owned, respectively. In the tropical domain, private ownership is relatively low at $21 \%$ and forest with unknown ownership is highest among the climatic domains at $15 \%$. It is likely that lack of clarify on forest ownership contributes to unsustainable use of forest resources and conversion to other land uses in the tropical domain.

\section{Forest certification}

Forest certification is an important tool to promote and demonstrate sustainable forest management that is monitored and verified independently. Certification provides assurance that the forest manager is investing in continuous improvement to ensure the use of best practices in managing forests that will result in stable forest production and conservation values ${ }^{4}$.

International forest certification has grown rapidly over the past two decades, driven by market demand for legal and sustainably produced timber particular in the developed countries. Total certified area increased from 51 million ha in 2000 to 435 million ha in 2020, meaning that just over 10\% of the world's total forest area is now covered by international forest management certification.

Forest certification has been and is still heavily biased towards the boreal and temperate domains. In 2000 , boreal and temperate forests accounted for $90 \%$ of the total certified forest area, and this share decreased slightly to $84 \%$ in 2020 . The rate of growth in certified forest area over the past decade was the highest in the tropical domain with a $68 \%$ increase, followed by subtropical forests with an increase of $44 \%$. Despite the increase, the extent of certified forest area in subtropical and tropical domains remains modest, comprising only 7.1 and $8.9 \%$ of the total certified area (Fig. 12). This is particularly low for tropical forests considering that they make up the largest portion of the global forest area at $45 \%$ and the substantial share of tropical hardwood in the global timber trade; tropical hardwood accounted for 24 percent of the global export value of industrial roundwood in $2019^{23}$.

The growth in forest certification has also been uneven when viewed by income categories. In $2000,90 \%$ of all certified forest areas were in high-income countries. By 2020 , this share has decreased to $70 \%$. During the past 10 years, certified forest area in upper middle-income countries expanded rapidly, by more than two-fold. Certified forest area in lower middle-income countries also increased considerably (by $72 \%$ during the same period), but the total certified area remain modest at $2.3 \%$ of the global total certified area. Certification remained practically non-relevant in low-income countries, with only four countries having any certified forests in 2020 totalling 175,000 ha, which accounted for only $0.04 \%$ of the global certified forest area (Fig. 12). 
Despite the substantial growth in certified forest area, forest certification has not succeeded in widening its reach in the tropical forests of lower middle-income and low-income countries where such marketbased instrument to promote sustainable production while addressing the environmental, social and cultural dimensions of forest management would provide the greatest value.

\section{Discussion}

There is evidence of generally positive progress towards sustainable forest management worldwide, indicated by the widespread presence of enabling framework for sustainable forest management, slowing of rate of forest loss in large deforesting countries, increase in forest area designated for protection and conservation, and the rapid growth of international forest certification. Global expansion of sustainable forest management is also confirmed through monitoring of SDG indicator 15.2.1 and reporting on achievement of Global Forest Goals under UNSPF${ }^{3}$.

However, masked behind the positive increase in most sustainable forest management indicators, forest loss is accelerating in the low-income and lower middle-income countries in the tropics. The gap between the wealthy and poorer countries are widening with deterioration of forest management in the lower income countries. Tropical forests continue to be lost while forests in boreal, temperate and subtropical domains expand. Tropical forests also suffer from widespread degradation, with over 156 million hectares (or $9 \%$ of the domain forest area) degraded between 2000 and 2012 compared to only $2 \%$ of the domain forest area degraded in boreal and subtropoical zones during the same period4.

There are several factors that contribute to the continued loss and degradation of tropical forests. Firstly, the proportion of forest area covered by long-term forest management plans, which is an indispensable tool to guide field-level operations and to ensure sustained supply of forest goods and services through long-term investment, remains particularly low in low-income tropical countries. Furthermore, significant proportion of forest in these countries do not have designated management objectives and are without clear ownership. Such condition will likely facilitate overexploitation of forest resources without concern for long-term sustainability. Extent of forest area designated as permanent forest estates also remains low in these geographies. Moreover, international forest certification schemes have made negligible impact in the low-income tropical countries where such market-based instrument to ensure sustainable production could provide the greatest value.

Data used in this study do not provide spatially explicit information that enable systematic evaluation of forest performance under different management objectives. However, findings clearly indicate that setting aside forest areas for conservation and protection is unlikely to be effective in maintaining forest cover unless there are adequate financial resources and institutional capacity to manage such areas. This supposition is supported by recent studies that show the mixed effectiveness of protected areas in resisting deforestation and conserving biodiversity. While protected areas in general have the effect of slowing deforestation, these areas are rarely strictly protected ${ }^{21}$. In many cases, anthropogenic pressures can be just as high, or even higher, inside protected areas compared to matched unprotected areas ${ }^{19,24,25}$. 
Effective protection of forest areas entails considerable costs, both direct and indirect, and it is unlikely that the full extent of these costs can be covered in developing countries as protected areas continue to increase ${ }^{17}$. While a network of protected areas is necessary for conserving representative areas of intact forests, a combination of response actions are needed to effectively maintain conservation values across landscapes.

Financing is identified as the most significant barrier to sustainable forest management in developing countries $^{3}$. Yet, low income countries have the lowest proportion of forest area allocated to production, which could potentially generate much needed revenues that can be reinvested in forestry. This may be due to the association of logging with forest destruction, particularly in the absence of adequate capacity and resources to monitor and regulate harvesting activities. Logging is indeed the primary driver of forest degradation, and the process of tropical deforestation often starts with unsustainable harvesting that depletes the economic value of the forest and provides access to forest interiors, which often ends with forest conversion to commercial agriculture ${ }^{11,26,27}$. However, it should be noted that in many cases logging is conducted to remove valuable timber as prelude to land clearing and conversion to permanent agriculture without the intention to maintain forest land use. Experience in many countries show that it is possible to manage production forests sustainably with safeguards in place to ensure legal and sustainable utilization of forest resources

The majority of tropical forests have been subjected to selective logging in most tropical regions s $^{28,29,30}$. Logged forests are often overlooked resource that can continue to generate financial benefits and incentives for local communities and forest managers to maintain forest land use, along with many intangible benefits that forests provide ${ }^{31}$. Sustainable and regulated timber harvesting have the potential to reduce illegal logging, encroachment and land conversion by making forest management an economically viable land use option. Numerous studies have shown that selectively logged tropical forests can retain substantial conservation values, which can be further enhanced through improved forest management ${ }^{29,32}$. In countries with inadequate forest law enforcement, signs of active forest management can deter encroachment by giving a clear signal that the forest is being utilized and is therefore not an open access resource.

Conservation through sustainable use is likely to be a more effective strategy for maintaining forested landscapes than setting aside forest areas for strict conservation, particularly where capacity and resources to effectively manage such areas are limited. Mosaic of forest areas managed through different approaches including reserves, intensive management, and ecological forestry or extensive management could serve to balance trade-offs among wood production, conservation and other competing objectives to deliver optimal outcomes at the landscape level ${ }^{33}$. Such combined approach would also encourage inclusive public-private-people partnerships that are needed to achieve positive outcomes across forested landscapes. Other effective area-based conservation measures (OECMs) and IUCN protected area management category VI may provide the framework for multiple use areas where 
conservation objectives could be combined with sustainable local use of forests and timber harvesting, with the active involvement of local communities in managing forests productively.

To advance sustainable forest management, particularly of tropical forests in lower income countries, the following approaches are proposed: 1) enhancing the role of well-managed production forest in maintaining forest cover and flow of ecosystem services within a broader forest landscape mosaic; 2) assigning a clear set of management objectives to all forest areas; 3 ) developing and implementing longterm forest management plans that are formulated and effectively implemented with meaningful engagement of stakeholders; and 4) managing more forest areas for multiple use to meet the needs for diverse forest products and services.

There is significant momentum building on forest and landscape restoration with ambitious restoration targets and commitments set by various government and private sector actors (e.g., the Bonn Challenge, New York Declaration on Forests, and the United Nations Decade on Ecosystem Restoration 2021-2030). These initiatives to restore and recover what has been lost should go together with efforts to maintain and improve the management of existing forests as the rate of deforestation and forest degradation far outpaces what we can hope to achieve through forest restoration efforts. Investing in sustainable forest management to conserve forest is more economical and ecologically less disruptive than to first degrade and then restore forest ecosystems.

Finally, the ongoing COVID-19 crisis may open opportunities for increased investment in forestry. Sustainable forest management can play a central role in social and economic recovery in the aftermath of the crisis. Designing programmes that combine employment opportunities with efforts to sustain and enhance forest productivity and environmental protection will be critical in building back stronger and more resilient communities and societies ${ }^{34}$.

\section{Methods}

Data from FAO's Global Forest Resources Assessment (FRA) 2020 were used extensively for the analyses presented in this paper. FRA 2020 included a total of 236 countries and territories based on the list used by the United Nations Statistics Division. The methods, definitions and approaches used in FRA 2020 are available at http://www.fao.org/forest-resources-assessment/en/. All data used in this paper was provided by countries or through desk studies carried out by FAO. FRA 2020 data is publically available at https://fra-data.fao.org/.

In FRA 2020, the analysis of forest area by climatic domains was carried out using FAO Global Ecological Zone map ${ }^{35}$ and the MODIS Vegetation Continuous Fields (VFC) pixels with a canopy cover larger than or equal to $10 \%$ to determine the forested area. Proportions of each country's forest area in boreal, temperate, subtropical and tropical domains were prefilled in the FRA country reports, and verified by the countries. Because FRA does not provide spatially explicit data, it was assumed that the reported areabased figures applied proportionately to each climatic domain present in the country if there were more 
than one. For example, if a country's forest was $50 \%$ boreal and $50 \%$ temperate, and the country reported a gain of 100 hectares of forest, it was assumed that there was a gain of 50 hectares each in the boreal and temperate domains.

To analyse data by national income levels, Gross National Income per capita was used as a categorical variable with four income categories defined by the World Bank ${ }^{36}$ : low-income economies (\$1035 or less), lower-middle (US\$1036-\$4045), upper-middle (US\$4046-\$12,535) and high-income economies (US\$12,536 or more). The most recent income category classification was used for all analyses although the income category classification of some countries have changed during the past 30 years. Of the 236 countries and territories included in FRA 2020, there were 24 countries and territories that are excluded in the World Bank categories. These countries and territories include only 0.97 million ha of forest, and these were not included in the income category-based analyses.

Data on forest area under independently verified forest management certification was provided to FAO by the secretariats of the Forest Stewardship Council (FSC) and the Programme for the Endorsement of Forest Certification (PEFC) as part of monitoring of a subindicator of Sustainable Development Goal indicator 15.2.1 ("progress towards sustainable forest management"). In this process, the two secretariats have undertaken a joint analysis of areas certified under both schemes, thereby making it possible to estimate the total certified forest area without bias due to double certification ${ }^{5}$.

\section{Declarations}

\section{Acknowledgements}

The author of this paper is grateful to guidance provided by Sheila Wertz-Kanounnikoff and comments provided by Jarkko Koskela on the draft manuscript.

\section{Competing interests}

The author declares no competing interests.

\section{References}

1. FAO. The State of the World's Forests 2018 - Forest pathways to sustainable development. Rome. Licence: CC BY-NC-SA 3.0 IGO (2018).

2. United Nations. Resolution adopted by the General Assembly on 17 December 2007 (A/RES/62/98) https://undocs.org/en/A/RES/62/98 (2007).

3. United Nations Department of Economic and Social Affairs, United Nations Forum on Forests Secretariat. The Global Forest Goals Report 2021 (2021). 
4. FAO. Global Forest Resources Assessment 2015: How are the world's forests changing? (Food and Agriculture Organization of the United Nations, Rome, 2015).

5. FAO. Global Forest Resources Assessment 2020: Main report (Food and Agriculture Organization of the United Nations, Rome, 2020).

6. MacDicken, K. G. et al. Global progress toward sustainable forest management. Forest Ecology and Management, 352, 47-56 (2015).

7. United Nations. The Sustainable Development Goals Report 2020. https://unstats.un.org/sdgs/report/2020/The-Sustainable-Development-Goals-Report-2020.pdf (2020)

8. Selkimäki, M., González-Olabarria, J. R., Trasobares, A. \& Pukkala, T. Trade-offs between economic profitability, erosion risk mitigation and biodiversity in the management of uneven-aged Abies alba Mill. Stands. Annals of Forest Science, 77, 12 https://doi.org/10.1007/s13595-019-0914-z (2020).

9. FAO. Developing effective forest policy - A guide (FAO Forestry Paper 161. Food and Agriculture Organization of the United Nations, Rome, 2010).

10. Börner, J., Schulz, D., Wunder, S. \& Pfaff, A. The Effectiveness of Forest Conservation Policies and Programs. Annual Review of Resource Economics, 12, 45-64 (2020).

11. Pacheco, P. et al. Deforestation fronts: Drivers and responses in a changing world (WWF, Gland, Switzerland, 2021).

12. FAO. NFP in practice - Ways to improve the implementation of national forest programmes (Food and Agriculture Organization of the United Nations, Rome, 2012).

13. Gilmour, D. Forty years of community-based forestry: A review of its extent and effectiveness (FAO Forestry Paper 176. Food and Agriculture Organization of the United Nations, Rome, 2016).

14. FAO. Terms and Definitions: FRA 2020. Forest Resources Assessment Working Paper 188. Food and Agriculture Organization of the United Nations, Rome (2018).

15. Macqueen, D. \& Mayers, J. Unseen foresters - an assessment of approaches for wider recognition and spread of sustainable forest management by local communities (WWF, Stockholm, Sweden, 2020).

16. Nasi, R. \& Frost, P. G. H. Sustainable forest management in the tropics: is everything in order but the patient still dying? Ecology and Society, 14 (2), 40 (2009).

17. Geldmanna, J., Manicab, A., Burgessa, N. D., Coadc, L. \& Balmforda, A. A global-level assessment of the effectiveness of protected areas at resisting anthropogenic pressures. PNAS, 116 (46), 2320923215 (2019).

18. Herreraa, D., Pfaffb, A. \& Robalinoc, J. Impacts of protected areas vary with the level of government: Comparing avoided deforestation across agencies in the Brazilian Amazon. PNAS, 116 (30), $14916-$ 14925 (2019).

19. Wolf, C., Levi, T., Ripple, W. J., Zárrate-Charry, D. A. \& Betts, M. G. A forest loss report card for the world's protected areas. Nature Ecology \& Evolution, https://doi.org/10.1038/s41559-021-01389-0 
(2021).

20. van Hensbergen, H. J. Rethinking forest concessions - Improving the allocation of state-owned forests for better economic, social and environmental outcomes. Forestry Working Paper No. 4. Rome, FAO(2018).

21. FAO. FAOSTAT http://www.fao.org/faostat/en/\#data/FO (2021)

22. Anderson, E. \& Mammides, C. The role of protected areas in mitigating human impact in the world's last wilderness areas., 49, 434-441 https://doi.org/10.1007/s13280-019-01213-x (2020).

23. Gaveau, D. L. A. et al. Reconciling forest conservation and logging in Indonesian Borneo. PLOS ONE, 8 (8), e69887 https://doi.org/10.1371/journal.pone.0069887 (2013).

24. Hosonuma, N. et al. An assessment of deforestation and forest degradation drivers in developing countries. Environ. Res. Lett, 7, 044009 https://doi.org/10.1088/1748-9326/7/4/044009 (2012).

25. Kleinschroth, F. \& Healey, J. R. Impacts of logging roads on tropical forests. BIOTROPICA, 49 (5), 620-635 https://doi.org/10.1111/btp.12462 (2017).

26. Asner, G. P., Rudel, T. K. \& Aide, T. M. A contemporary assessment of change in humid tropical forests. Conserv. Biol, 23 (6), 1386-1395 https://doi.org/10.1111/j.1523-1739.2009.01333.x (2009).

27. Putz, F. E. et al. Sustaining conservation values in selectively logged tropical forests: the attained and the attainable. Conservation Letters, 5 (4), 296-303 https://doi.org/10.1111/j.1755263X.2012.00242.x (2012).

28. Wu, J. et al. Monitoring tropical forest degradation and restoration with satellite remote sensing: A test using Sabah Biodiversity Experiment. Advances in Ecological Research, 62, 117-146 (2020).

29. Gräfe, S. et al. Sustainable management of logged tropical forests in the Caribbean to ensure longterm productivity. Forestry Working Paper No. 27. Food and Agriculture Organization of the United Nations, Rome(2021).

30. Putz, F. E. et al. Intact Forest in Selective Logging Landscapes in the Tropics. Frontiers in Forests and Global Change, 2, 30 https://doi.org/10.3389/ffgc.2019.00030 (2019).

31. Betts, M. G. et al. Producing wood at least cost to biodiversity: integrating Triad and sharing-sparing approaches to inform forest landscape management. Biol. Rev, 96 (4), 1301-1317 https://doi.org/10.1111/brv.12703 (2021).

32. FAO. The impacts of COVID-19 on the forest sector: How to respond? https://doi.org/10.4060/ca8844en (2020).

33. FAO. Global Ecological Zones for FAO Forest Reporting: 2010 Update. Prepared by S. Iremonger. Forest Resources Assessment Working Paper 179. Rome (2020).

34. World Bank. https://datahelpdesk.worldbank.org/knowledgebase/articles/906519 (2021).

\section{Figures}




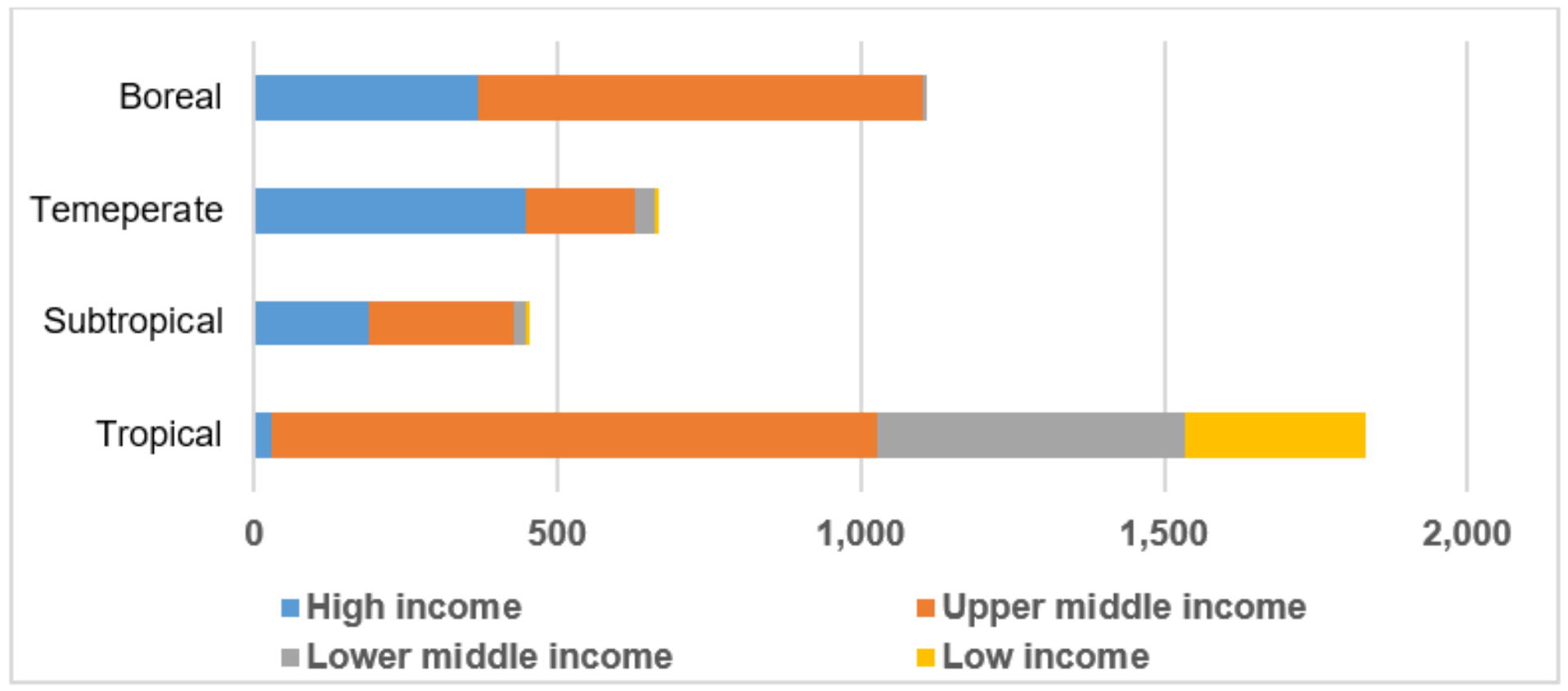

\section{Figure 1}

Global forest area by climatic domain and income, 2020 (million ha)

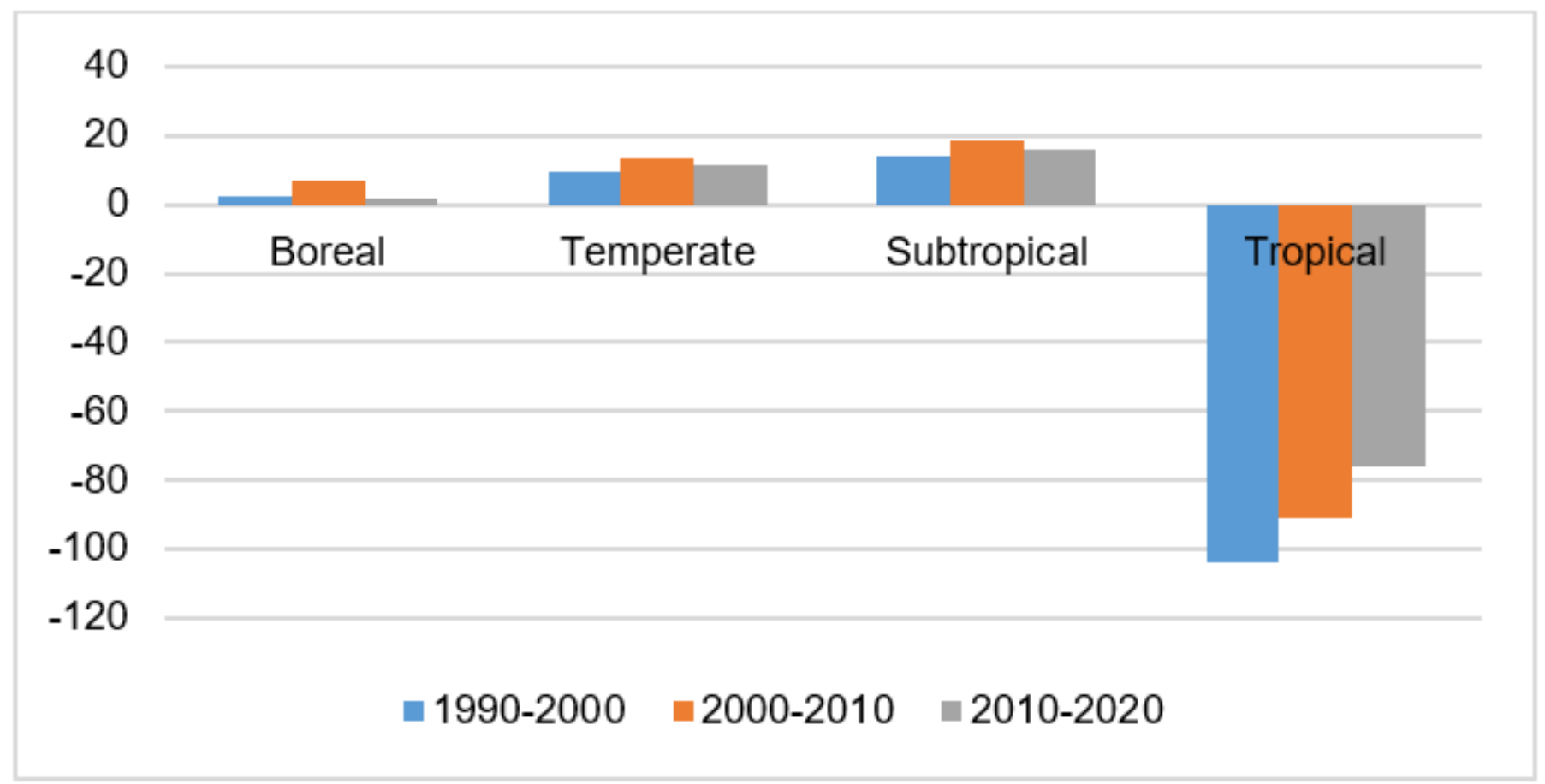

Figure 2

Net change in total forest area by climatic domain (million ha/year) 


\section{0}

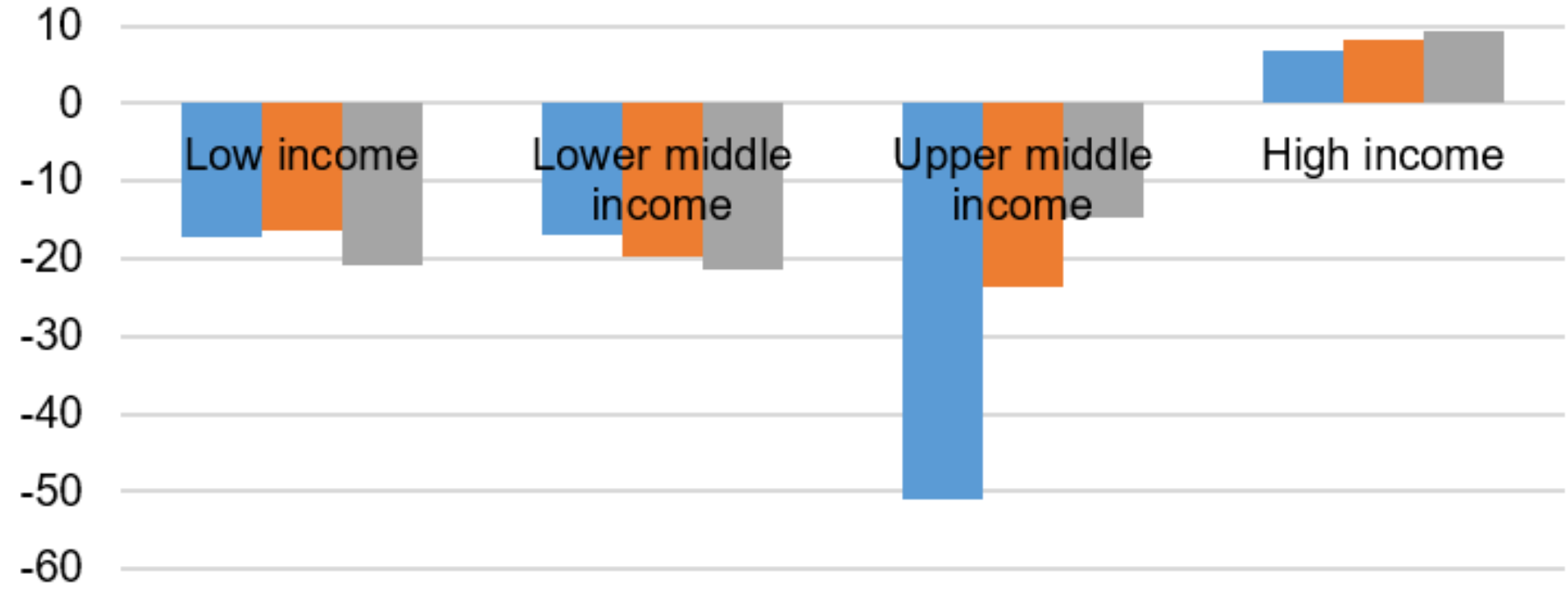

\section{Figure 3}

$1990-2000 \approx 2000-2010 \approx 2010-2020$

Net change in total forest area by income (1,000 ha)

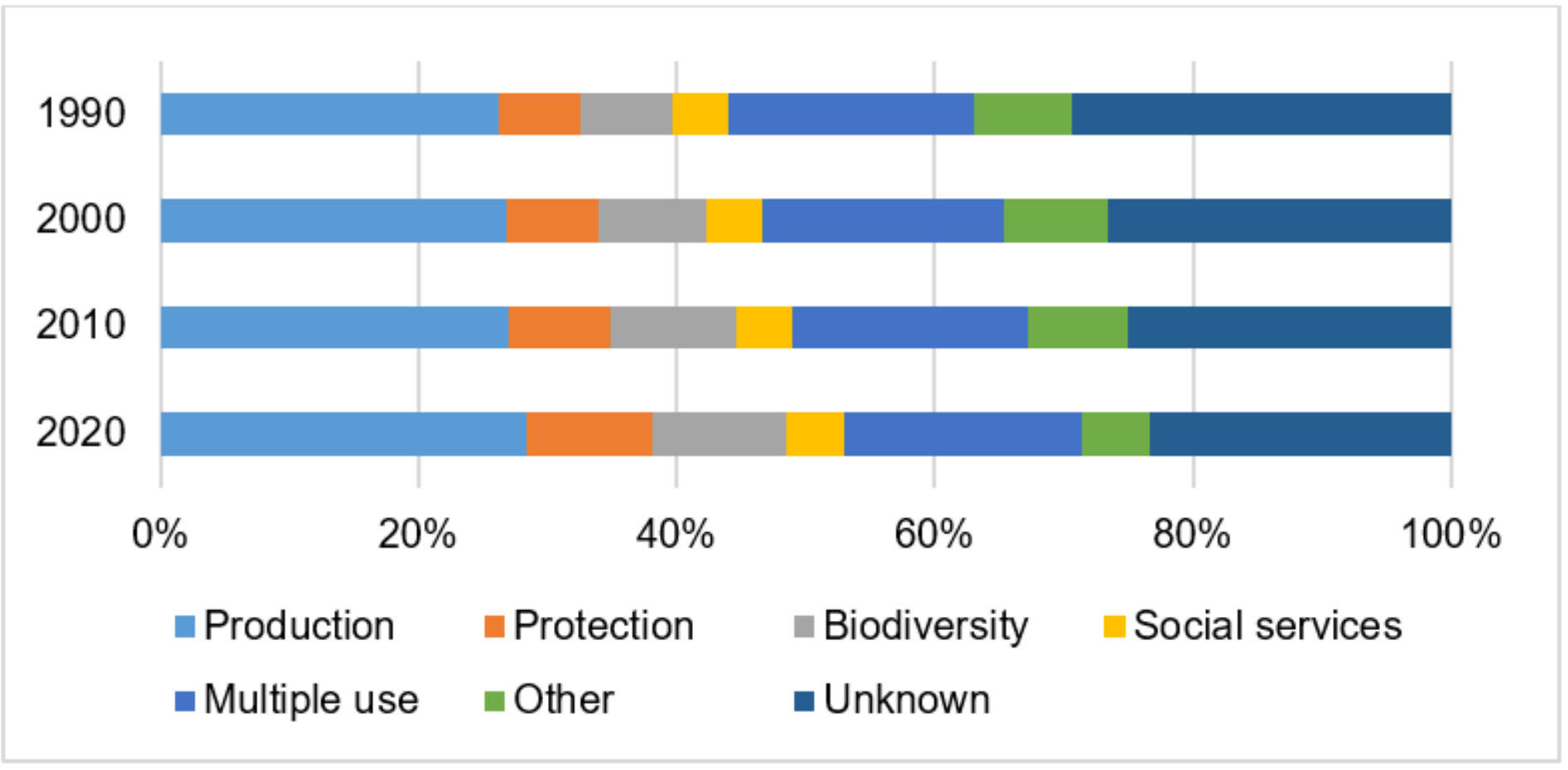

Figure 4

Proportion of total forest area designated for various primary management objectives, 1990-2020 


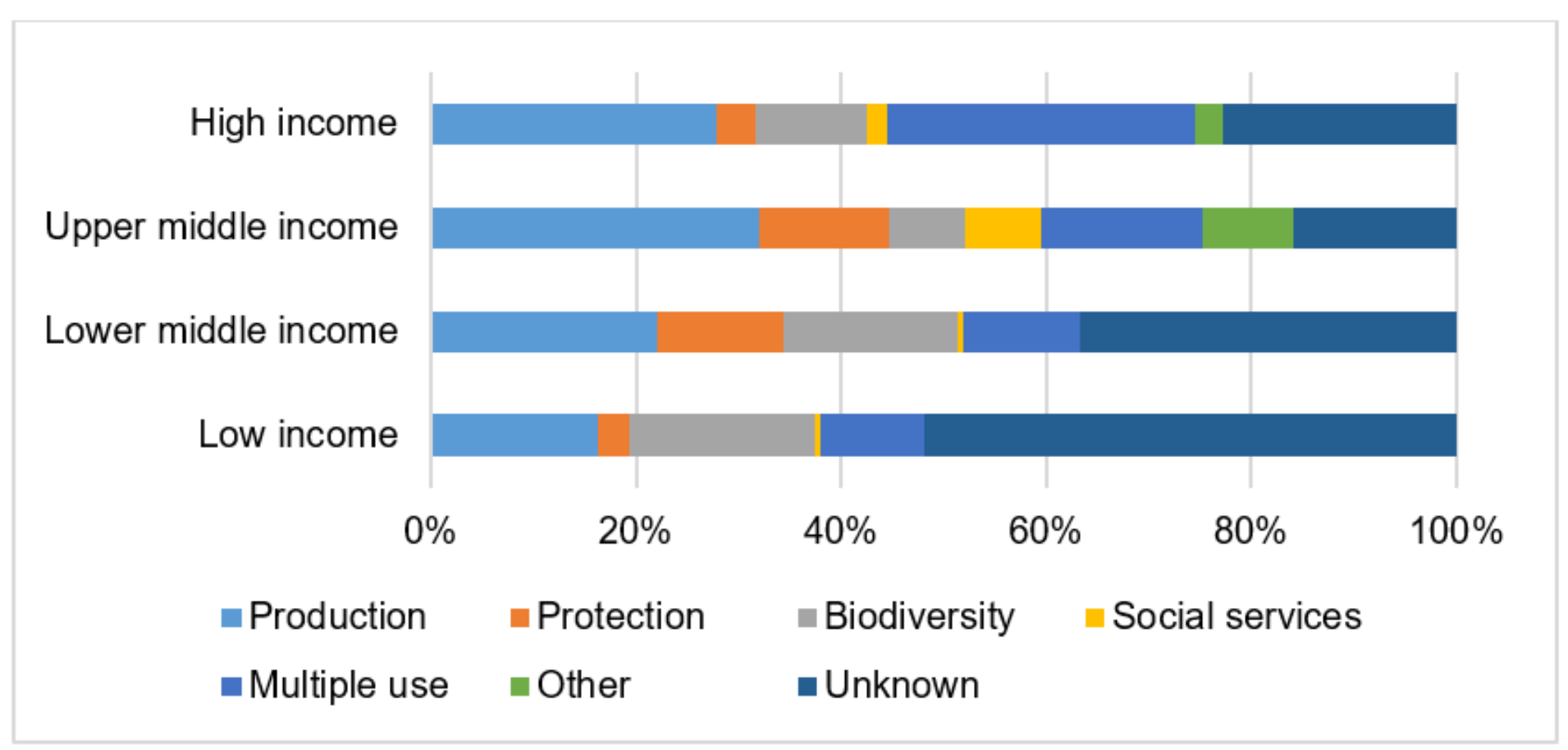

\section{Figure 5}

Proportion of total forest area designated for various primary management objectives by income, 2020

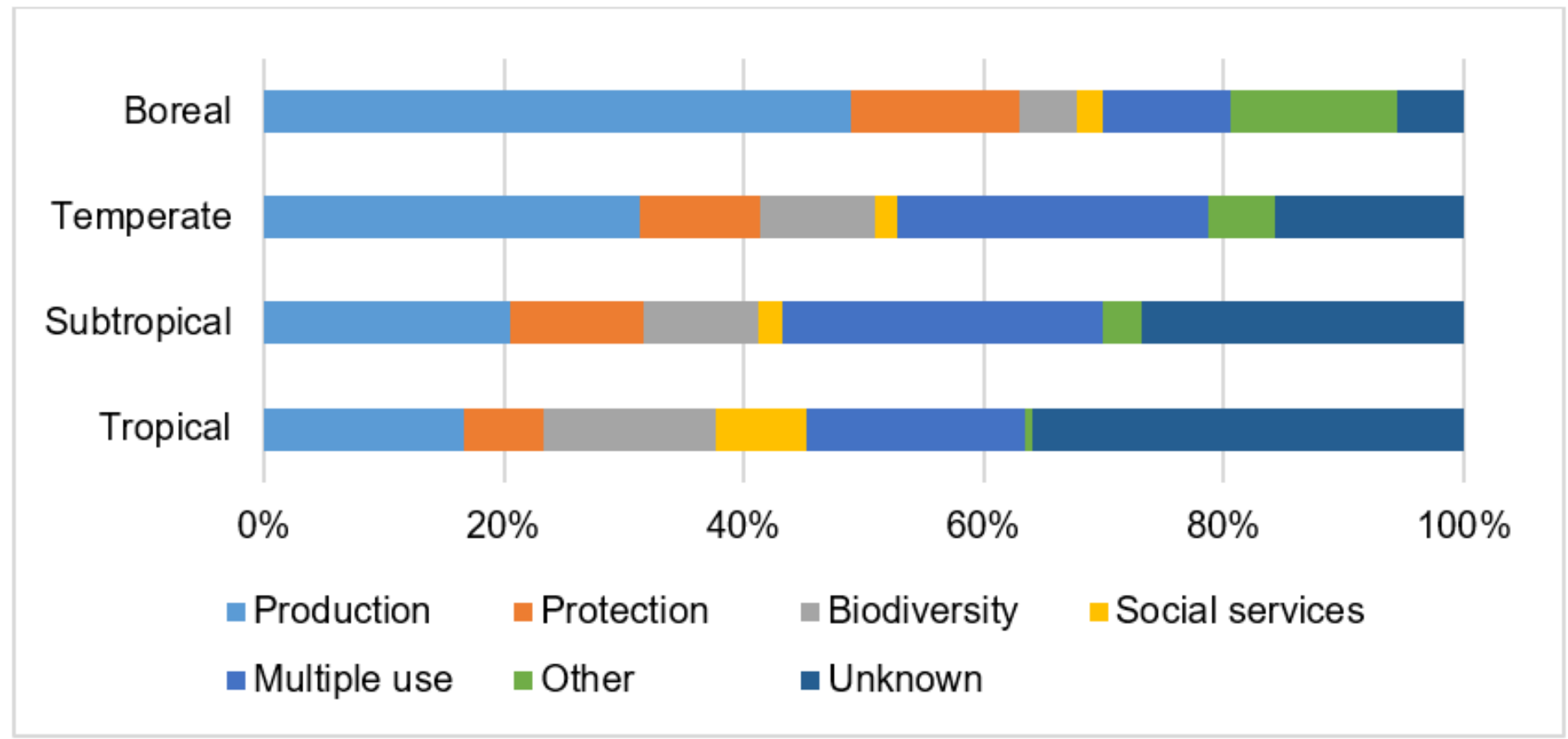

\section{Figure 6}

Proportion of total forest area designated for various primary management objectives by climatic domain, 2020 
2,500

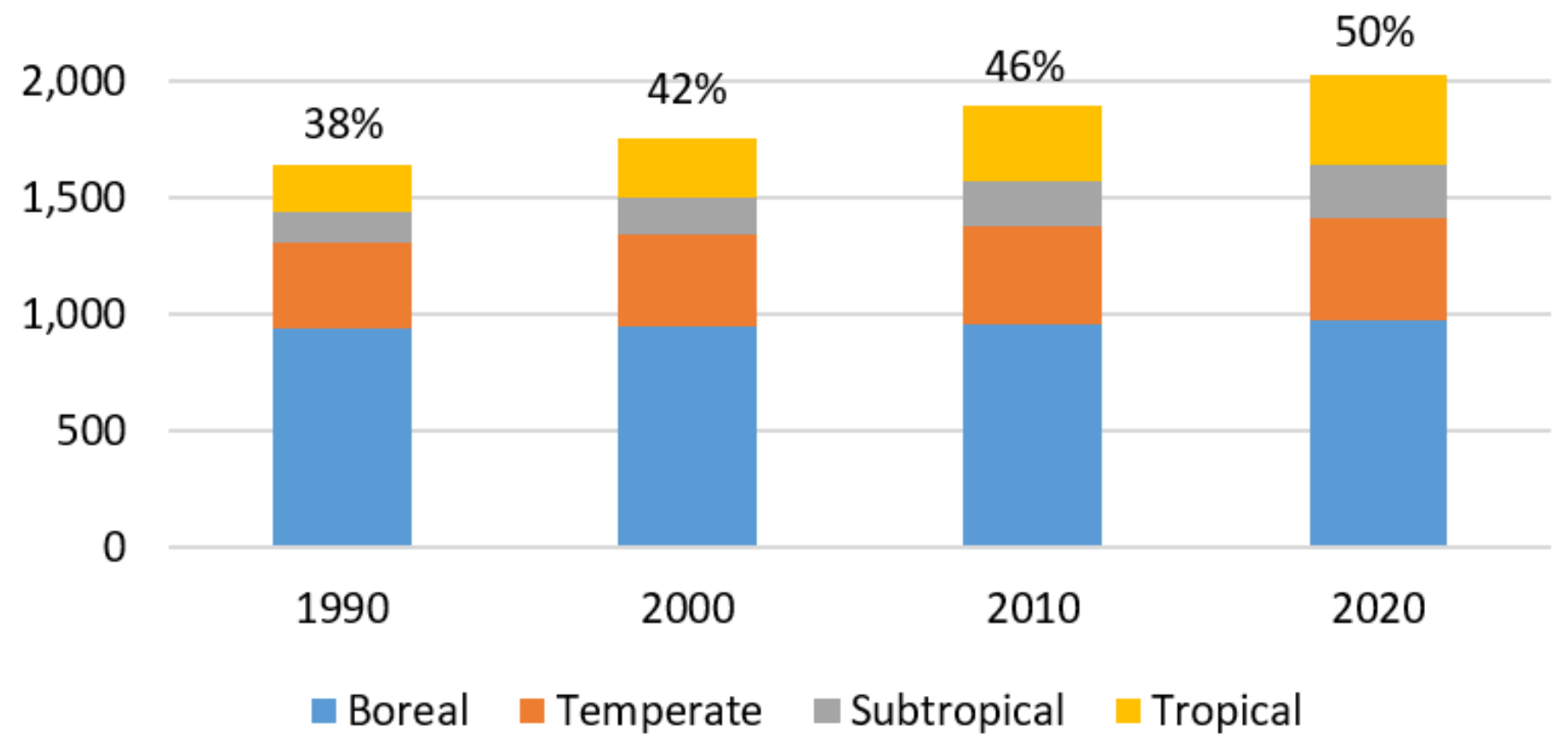

Figure 7

Total forest area covered by forest management plans 1990-2020 (million ha)
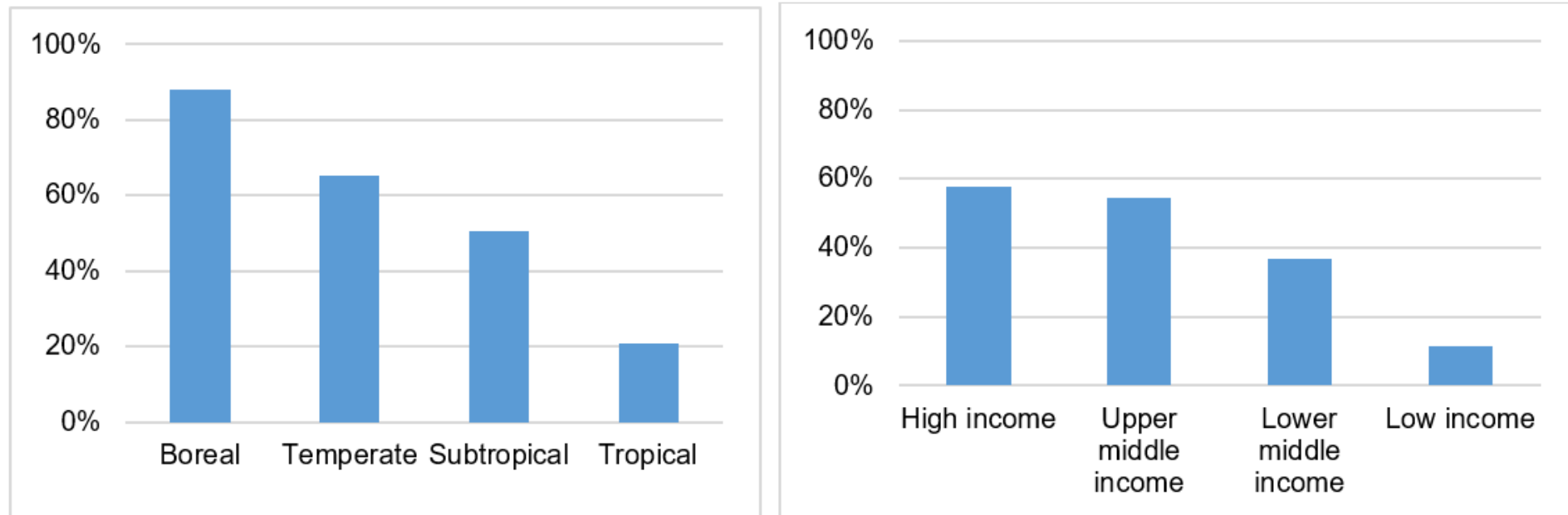

\section{Figure 8}

Proportion of total forest area covered by long-term forest management plans by climatic domain and income, 2020 


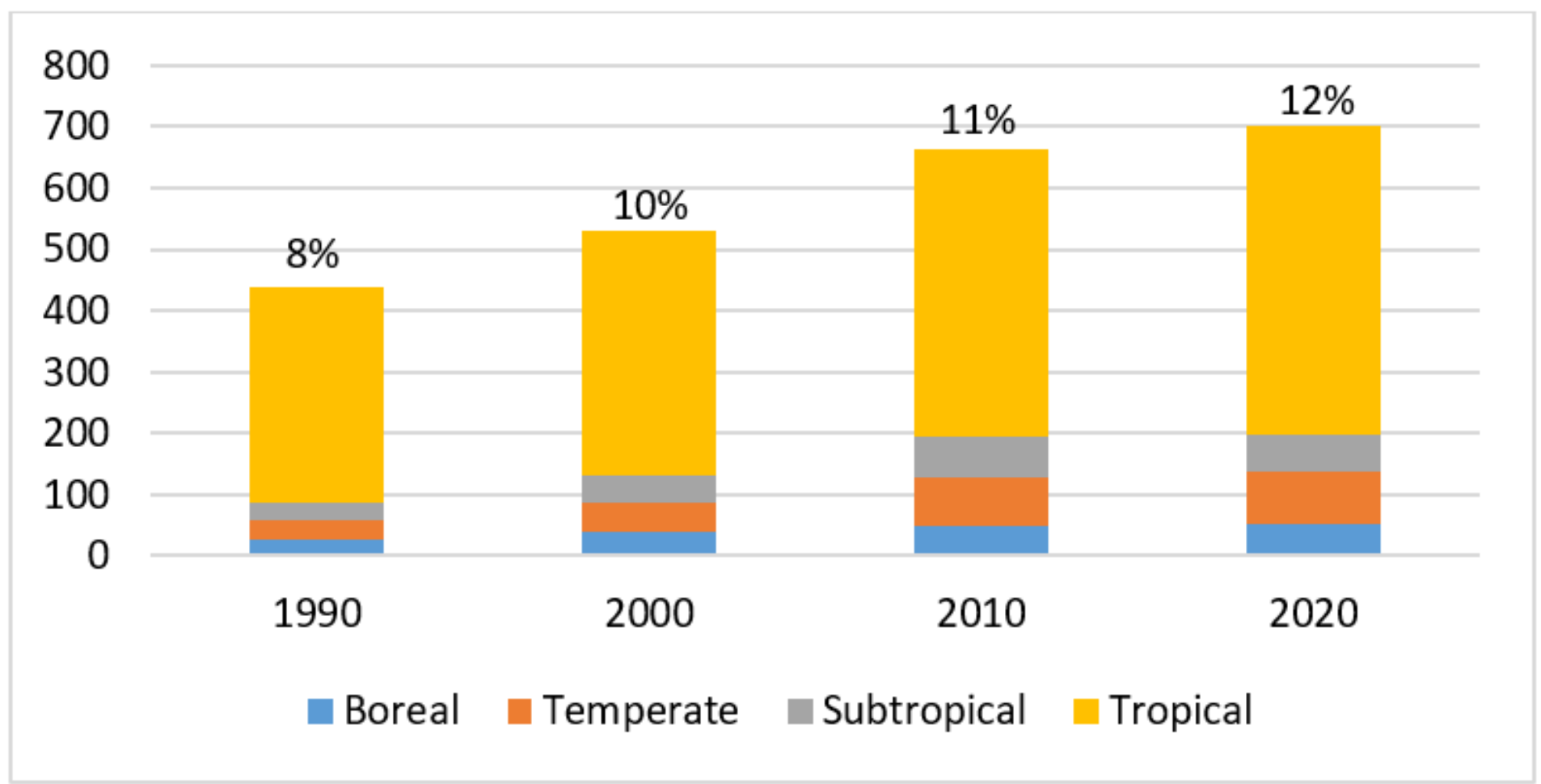

\section{Figure 9}

Total forest area within legally established protected areas 1990-2020 (million ha)

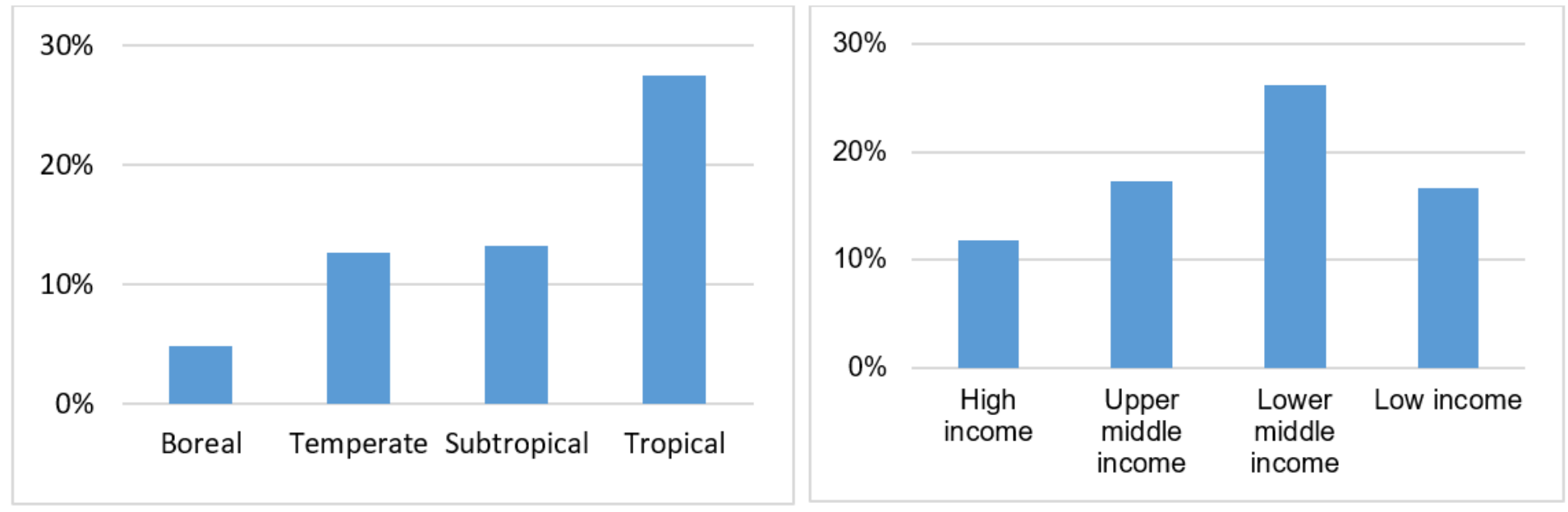

\section{Figure 10}

Proportion of forest in protected areas by climatic domain and income, 2020. 


\begin{tabular}{|c|c|c|c|c|c|c|}
\hline 500 & & & 500 & & & \\
\hline 400 & & & 400 & & & \\
\hline 300 & & & 300 & & & \\
\hline 200 & & & & & & \\
\hline 100 & & 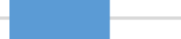 & & & & \\
\hline 0 & & & & 2000 & 2010 & 2020 \\
\hline 2000 & 2010 & 2020 & & High-income & $\square \mathrm{up}$ & e-income \\
\hline$\square$ Boreal $\square$ Temperate & Subtropical & $\square$ Tropical & & Lower middle & e $\square$ Lo & \\
\hline
\end{tabular}

\section{Figure 11}

Certified forest area in 2000, 2010 and 2020 by climatic domain and income (million ha) 